Original article

https://www.journal-imab-bg.org

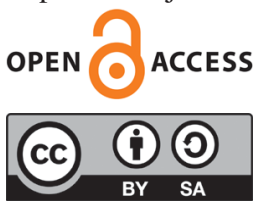

\title{
ANTIMICROBIAL EFFECT OF A MEANS FOR ENZYME EXCAVATION (BRIX 3000) AND PHO- TODYNAMIC THERAPY IN CARIOUS LESIONS OF PRIMARY TEETH - IN VITRO EXPERIMENT
}

\author{
Zornitsa Lazarova ${ }^{1}$, Maya Rashkova ${ }^{1}$, Raina Gergova ${ }^{2}$, Virna-Maria Stavros \\ Tsitou $^{2}$ \\ 1) Department of Pediatric Dentistry, Faculty of dental medicine, Medical Uni- \\ versity - Sofia, Bulgaria. \\ 2) Department of Medical Microbiology, Faculty of Medicine, Medical Univer- \\ sity - Sofia, Bulgaria.
}

\begin{abstract}
The selective removal of the caries dentin via enzyme methods for excavation appears to be an alternative to the conventional treatment of carious lesions in childhood. Photodynamic therapy is an effective alternative for the reduction of cariesogenic microorganisms. Brix 3000 is an enzyme-based material for excavation of carious dentin.

Aim: To study the antimicrobial effect of means for enzyme excavation (Brix 3000) and photodynamic therapy with FotoSan 630 Intro Kit to the two main cariesogenic microorganisms $-S$. mutans and L. acidophilus, in vitro experiment;

Materials and Methods: Eighty plates were prepared: group 1- 20 plates only with Brix 3000; group 2 20 plates only with FotoSan; group $3-20$ plates with a combination of Brix 3000 and FotoSan; group $4-20$ plates without an active agent.

In the agar of each plate, three $7 \mathrm{~mm}$ wells in diameter were made, where the Brix 3000 gel was placed, as well as discs soaked with the dye and irradiated with FotoSan and a combination of them. After 24 hours, the zone of inhibition was measured.

Results: Compared to the control group, Brix 3000 and FotoSan have a defined antimicrobial activity against S. mutans and Lactobacillus spp. By combining the two materials, their antimicrobial activity significantly increases. S. mutans shows greater resistance compared to Lactobacillus spp.

Conclusion: A combination of enzyme-based excavation and photodynamic therapy could be used successfully in the treatment of carious lesions in primary teeth.
\end{abstract}

Keywords: S. mutans, Lactobacillus spp., photodynamic therapy, Brix 3000,

\section{INTRODUCTION}

The philosophy of minimally invasive treatment is expressed in maximum preservation of hard dental structures in the treatment of carious lesions and stimulating tertiary dentinogenesis $[1,2]$. An important step is the selec- tive removal of carious dentin by enzyme-based methods, which turns out to be a reliable alternative to conventional treatment, especially to children with primary teeth [3]. During the excavation, the number and quantity of cariogenic microorganisms are reduced, decreasing the risk of unnecessary disclosure of the pulp during treatment. In the carious lesion, conditions are created for stationing the process[4].

Photodynamic therapy turns out to be an effective alternative for the reduction of cariogenic microorganisms. This technique is based on the use of a light source to activate a photosensitizer, which in the presence of oxygen, produces nascent oxygen and free radicals that irreversibly damage cellular components and change the metabolic properties of the microbial cell leading to its death $[5,6]$. The most important characteristic of the interaction of biological tissue with the molecules of photosensitizing agents is in the selective attacking only the damaged microbial cells $[7,8]$.

Brix 3000 is enzyme-based material for chemo-mechanical excavation. Its main component is papain, which is bio-encapsulated by EBE Technology (Encapsulating Buffer Emulsion). This technology releases the enzyme, generation proteolysis to the carious dentin. When the gel meets healthy dentin, it loses its enzyme properties due to the presence of antiprotease-1-antitrypsin. In this way, Brix 3000 acts selectively, preserving the partially degraded collagen in the dentin, which can be remineralized.

Clinical removal of carious dentin, in which enzymebased excavation with Brix 3000 and photodynamic therapy for disinfection during treatment, is a reliable alternative to the conventional treatment.

\section{Aim}

To study the antimicrobial effect of means for enzyme excavation (Brix 3000) and photodynamic therapy with FotoSan 630 Intro Kit to the two main cariesogenic microorganisms $-S$. mutans and L. acidophilus, in vitro experiment. 


\section{MATERIAL}

For the experimental study of the antimicrobial efficacy of Brix 3000 and PDT with FotoSan 630 Intro Kit, 80 plates were prepared, grouped as follows:

- Group 1 - 10 plates each inoculated with S. mutans and Lactobacillus spp. processed with Brix 3000;

- Group 2 - 10 plates each inoculated with $S$. mutans and Lactobacillus spp. processed with FotoSan 630 Intro Kit;

- Group 3 - 10 plates each inoculated with S. mutans and Lactobacillus spp. treated with the combination Brix 3000 + FotoSan 630 Intro Kit;

- Group 4 - 10 plates each inoculated with S. mutans and Lactobacillus spp. without an active agent-control group

\section{MICROBIOLOGICAL METHOD:}

Lyophilized strains of $S$. mutans and Lactobacillus spp. come to life after culturing in broth and repeated subculturing of blood agar and $\mathrm{CO}_{2}$ atmosphere. After obtaining a pure 24-hour culture, it was standardized according to McFarlan 0.5 Mueller-Hinton agar plates (EUCAST 2020) were inoculated with $5 \%$ horse blood and $20 \mathrm{mg} / \mathrm{I}$ NAD using a sterile tampon.

In the agar of each plate were made three wells with a diameter of $7 \mathrm{~mm}$., where the Brix 3000 gel was applied, as well as discs soaked with the dye and irradiated with FotoSan (photodynamic therapy) and the combination of them.

The formulation thus prepared was incubated for 2448 hours in a thermostat at $36^{\circ} \mathrm{C}$ in a $\mathrm{CO}_{2}$ atmosphere. Inhibition zones were reported, including a well with a diameter of $7 \mathrm{~mm}$. and the zone of actual inhibition. The av- erage of the zones of inhibited growth was calculated in each group.

Image 1. Zone of inhibition obtained by the combined action of Brix 3000 and FotoSan

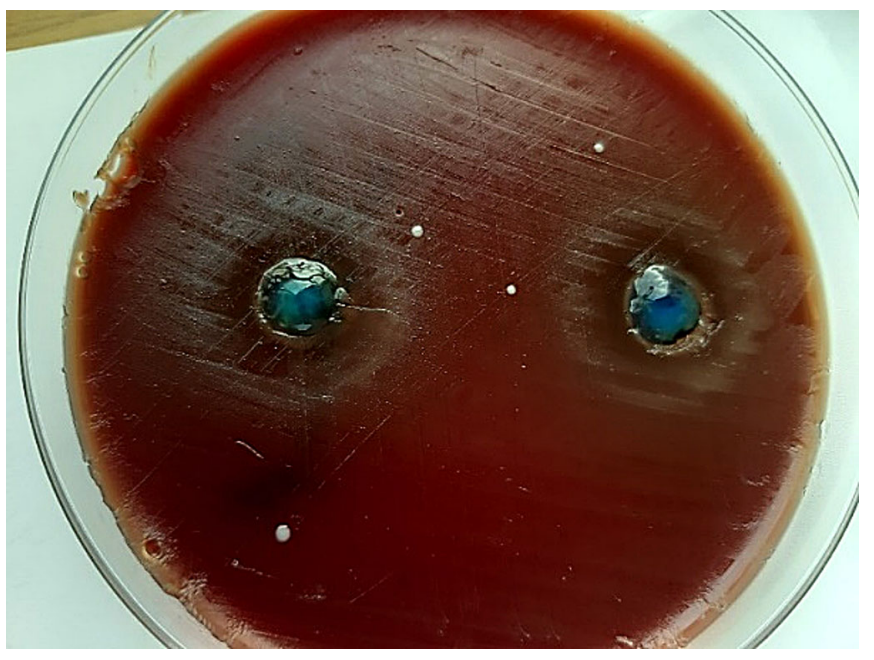

The SPSS (version 19, SPSS Inc., USA) was used for the statistical processing of the results. A $95 \%$ confidence interval $(\mathrm{p}<0.05)$ was chosen as a level of significance at which the null hypothesis is rejected.

\section{RESULTS}

1. Antimicrobial activity of Brix 3000, FotoSan and their combination to $S$. mutans

The next table represents the values of reported zones of $S$. mutans inhibition growth in millimeters.

Table 1. Antimicrobial activity of Brix 3000, PDT with FotoSan and their combination to S. mutans

\begin{tabular}{|c|c|c|c|}
\hline \multicolumn{4}{|c|}{ Average arithmetic values of the zone of inhibition, in $\mathrm{mm}$} \\
\hline Group & $\mathrm{N}$ & Mean \pm SD & Ind T-test \\
\hline Group 1 - Brix 3000 & 10 & $9.60 \pm 0.699$ & $\mathrm{t}_{1,2}=4.837 \quad \mathrm{p}_{1,2}<0.05$ \\
\hline Group $2-$ FotoSan & 10 & $8.30 \pm 0.483$ & $\mathrm{t}_{1,3}=-20.813 \mathrm{p}_{1,3}<0.05$ \\
\hline Group 3 - Brix 3000+FotoSan & 10 & $17.20 \pm 0.919$ & $\mathrm{t}_{1,4}=11.759 \quad \mathrm{p}_{1,4}<0.05$ \\
\hline Group 4 - control group & 10 & $7.00 \pm 0.00$ & $\begin{array}{ll}\mathrm{t}_{2,3}=-27.110 & \mathrm{p}_{2,3}<0.05 \\
\mathrm{t}_{2,4}=8.510 & \mathrm{p}_{2,4}<0.05 \\
\mathrm{t}_{3,4}=35.101 & \mathrm{p}_{3,4}<0.05\end{array}$ \\
\hline
\end{tabular}

The average value of the antimicrobial activity of Brix 3000 only against $S$. mutans is $9.60 \mathrm{~mm}$. The antimicrobial activity of Brix 3000 is double when compared to that of FotoSan, in separate usage. The best antimicrobial effect could be observed in ingroup 3, which includes a combination between Brix 3000 and FotoSan $(\mathrm{p}<0.05)$.
2. Researching the antimicrobial activity of Brix 3000 , FotoSan and their combination to Lactobacillus spp.

Table 2 presents the antimicrobial activity of Brix 3000, FotoSan and their combination to Lactobacillus spp. 
Table 2. Antimicrobial activity of Brix 3000, FotoSan and their combination to Lactobacillus spp.

\begin{tabular}{|c|c|c|c|}
\hline \multicolumn{4}{|c|}{ Average arithmetic values of the zone of inhibition, in $\mathrm{mm}$} \\
\hline Group & $\mathrm{N}$ & Mean \pm SD & Ind T-test \\
\hline Group 1 - Brix 3000 & 10 & $11.20 \pm 0.789$ & $\mathrm{t}_{1,2}=8.547$ \\
\hline Group 2 - FotoSan & 10 & $8.70 \pm 0.483$ & $\mathrm{t}_{1,3}=-20.889 \quad \mathrm{p}_{1,3}<0.05$ \\
\hline Group 3 - Brix 3000+FotoSan & 10 & $19.20 \pm 0.919$ & $\mathrm{t}_{1,4}=16.837 \quad \mathrm{p}_{1,4}<0.05$ \\
\hline Group 4 - control group & 10 & $7.00 \pm 0.00$ & $\begin{array}{ll}\mathrm{t}_{2,3}=-31.983 & \mathrm{p}_{2,3}<0.05 \\
\mathrm{t}_{2,4}=11.129 & \mathrm{p}_{2,4}<0.05 \\
\mathrm{t}_{3,4}=41.983 & \mathrm{p}_{3,4}<0.05\end{array}$ \\
\hline
\end{tabular}

Used separately, Brix 3000 demonstrates a higher antimicrobial activity compared to FotoSan $(\mathrm{p}<0.05)$. The two materials combined have higher antimicrobial activ- ity in comparison to their individual use.

3. Comparative analysis between the antimicrobial activity of S. mutans and Lactobacillus spp.

Table 3. Comparison of the antimicrobial activity of Brix 3000, FotoSan and their combination to S. mutants and Lactobacillus spp.

\begin{tabular}{|c|c|c|c|c|c|}
\hline \multirow{2}{*}{ Group } & \multicolumn{2}{|c|}{ S. Mutans } & \multicolumn{2}{c|}{ Lactobacillus sp. } & \multirow{2}{*}{ Paired S-test } \\
\cline { 2 - 5 } & $\mathrm{N}$ & Mean \pm SD & $\mathrm{N}$ & Mean \pm SD & \\
\hline Group 1 - Brix 3000 & 10 & $9.60 \pm 0.699$ & 10 & $11.20 \pm 0.789$ & $\mathrm{t}=-9.798 \mathrm{p}=0.000$ \\
\hline Group 2 - FotoSan & 10 & $8.30 \pm 0.483$ & 10 & $8.70 \pm 0.483$ & $\mathrm{t}=-2.449 \mathrm{p}=0.037$ \\
\hline Group 3 - Brix 3000+FotoSan & 10 & $17.20 \pm 0.919$ & 10 & $19.20 \pm 0.919$ & $\mathrm{t}=-13.416 \mathrm{p}=0.000$ \\
\hline Group 4 - control group & 10 & $7.00 \pm 0.00$ & 10 & $7.00 \pm 0.00$ & \\
\hline
\end{tabular}

It could be observed from the table that the antimicrobial activity of Brix 3000, used separately, is higher than Lactobacillus spp. when compared to S. mutans. FotoSan demonstrates a relatively similar antimicrobial activity to both microorganisms. The stronger antimicrobial effect of the combination of both materials used simultaneously is to Lactobacillus spp.

\section{DISCUSSION}

Our results revealed that both Brix 3000 and FotoSan possess an expressed activity with regards to the two main studied microorganisms, S. mutans and Lactobacillus spp. The papain, which is the main component of Brix 3000 , is an end protein with bacteriostatic, bactericidal and antiinflammatory activity. $[9,10]$. The papain could inhibit the growth of the bacteria since it could degrade the peptide bonds in microorganisms to dipeptides and amino acids. The enzyme papain is included in the sulfhydryl proteases group. This shows that it has a sulfhydrylene residue in its active place, which affects the bacterial cell wall and the cytoplasmic membrane [11].

The essence of photodynamic therapy is the creation of free radicals or of the active oxygen with a short life span. These radicals cause the immediate death of the cell, in which the photosensitizer lies. They have a very short life span and could be deactivated very rapidly, and thus they do not endanger the neighboring cells [11].

Brix 3000 has a higher antimicrobial activity to $S$. mutans and Lactobacillus spp in comparison to the photo- dynamic therapy as an individual activity. When the two materials are combined, the activity is increased. This proves a potentiated antimicrobial effect of the combination between Brix 3000 and photodynamic therapy with FotoSan to both microorganisms - S. mutans and Lactobacillus spp.

A number of studies prove the antimicrobial activity of the papain, which is the main component of Brix 3000. Goyal et al. compare the conventional method of excavation with the enzyme one by studying 25 children aged between 5 and 9 years. The microbiological samples are taken before and after excavation of the carious dentine. The results obtained reveal a significant reduction in the number and amount of S. mutans and Lactobacillus spp. [12]. Similar results are also achieved by Singh et al. by discovering a reduction in the amounts of S. Mutans and Lactobacillus spp. [13].

Various authors conduct in vitro studies of the antimicrobial effect of the photodynamic therapy against $S$. mutansandLactobacillussppby researching different sources of light and different photosensitizers. Araujo et al. demonstrate a high antimicrobial effect of the photodynamic therapy to S. Mutans and Lactobacillus spp. by using curcumin as a photosensitizer and blue light with wavelength $450 \mathrm{~nm}$ [14]. In their research, Melo et al.use a diode laser and toluidine blue and prove the high antimicrobial effect of the photodynamic therapy [15]. Their results concur with ours. The same results are achieved by Ricatto et al.in their work, although they use methylene blue as 
photosensitizer [16].

The chemio-mechanical technique of excavation of the carious dentine with Brix 3000 in primary teeth demonstrates excellent results in the context of the minimally invasive method. Through the technique, a controlled excavation of the completely damaged dentine only, and only the dentine, which could stimulate a tertiary dentinogenesis and internal remineralization, is reserved.

The potentiated antimicrobial effect, proven by us, of the means of enzyme excavation and follow-up procedure of photodynamic therapy with FotoSan, represents a good reason to recommend the studied means in selective excavation to soft, partially infected dentine in the course of treatment of deep dentine caries or asymptomatic closed pulpitis. The method is sparing and achieves dentine reserving for internal remineralization and stimulation of the tertiary dentinogenesis as well as a healing process on the part of the dental pulp.

\section{CONCLUSIONS:}

Brix 3000 for enzyme excavation has a two times higher antimicrobial activity when compared to FotoSan, used separately, to $S$. mutans and Lactobacillus spp;

By combining Brix 3000 with photodynamic therapy with FotoSan, their antimicrobial activity is significantly increased;

S. mutans is more resilient to Brix 3000 and the photodynamic therapy with FotoSan in comparison to Lactobacillus spp.

This contribution is published in accordance with project Grant-2019 with Contract No.86/23.04.2019 themed "Micro-invasive and Antimicrobial Effect of Chemo-mechanical Excavation Means in Primary Teeth Caries."
Abbreviations:
PDT - photodynamic therapy

\section{REFERENCES:}

1. Giacaman RA, Muñoz-Sandoval C, Neuhaus KW, Fontana M, Chaias R. Evidence-based strategies for the minimally invasive treatment of carious lesions: Review of the literature. Adv Clin Exp Med. 2018 Jul;27(7):1009-1016. [PubMed]

2. Schwendicke F. Removing Carious Tissue: Why and How? Monogr Oral Sci. 2018; 27:56-67. [PubMed]

3. Bussadori SK, Castro LC, Galvão AC. Papaingel: A newchemo-mechanical caries removal agent. J Clin Pediatr Dent. 2005 Winter;30(2):115-9. [PubMed]

4. Motta LJ, Bussadori SK, Campanelli AP, Silva AL, Alfaya TA, Godoy $\mathrm{CH}$, et al. Efficacy of Papacarie(®) in reduction of residual bacteria in deciduous teeth: a randomized, controlled clinical trial. Clinics (Sao Paulo). 2014; 69(5):319-22. [PubMed]

5. de Oliveira AB, Ferrisse TM, Marques RS, de Annunzio SR, Brighenti FL, Fontana CR. Effect of Photodynamic Therapy on Microorganisms Responsible for Dental Caries: A Systemic Review and Meta-Analysis. Int J Mol Sci. 2019 Jul 23; 20(14): 3585. [PubMed]

6. Alves LVGL, Curylofo-Zotti FA, Borsatto MC, Salvador SLS, Valerio RA, Sauza-Gabriel AE et al. Influence of antimicrobial photodynamic therapy in carious le- sion. Randomized split-mouth clinical trial in primary molars. Photodiagnosis Photodyn Ther. 2019 Jun;26:124-130. [PubMed]

7. Konopka K, Goslinski T. Photodynamic therapy in dentistry. J Dent Res. 2007 Aug;86(8):694-707. [PubMed]

8. Hamblim MR. Antimicrobial photodynamic inactivation: a bright new technique to kill resistant microbes. Curr Opin Microbiol. 2016 Oct;33:67-73. [PubMed]

9. Bittencourt ST, Pereira JR, Rosa AW, Oliveira KS, Ghizoni JS, Oliveira MT. Mineral content removal after Papacarie application in primary teeth: a quantitative analysis. J Clin Pediatr Dent. 2010 Spring; 34(3):229-31. [PubMed]

10. Costa-Santos L, Silva-Junior ZS, Sfalcin RA, Mota ACCD, Horliana ACRT, Motta LJ, et al. The effect of antimicrobial photodynamic therapy on infected dentin in primary teeth: A randomized controlled clinical trial protocol. Medicine (Baltimore). 2019 Apr;98(15):e15110. [PubMed]

11. Peters MC, Flamenbaum MH, Eboda NN, Feigal RJ, Inglehart MR. Chemo-mechanical caries removal in children: efficacy and efficiency. J Am Dent Assoc. 2006 Dec; 137(12):1658-66. [PubMed]

12. Goyal PA, Kumari R, Kannan VP,
Madhu S. Efficacy and Tolerance of Papain Gel with conventional Drilling Method: a clinico-microbiological study. J Clin Pediatr Dent. 2015 Winter;39(2):109-12. [PubMed]

13. Singh S, Singh DJ, Jaidka S, Somani R. Comparative clinical evaluatio of chemo-mechanical caries removal agent Papacarie ${ }^{\circledR}$ with conventional method among rural population in India - in vivo study. Braz, J Oral Sci. 2011;10(3):193-98.

14. Araujo NC, Fontana CR, Gerbi ME, Bagnato VS, Overall-mouth disinfection by photodynamic therapy using curcumin. Photomed Laser Surg. 2012 Feb;30(2):96101. [PubMed]

15. Melo MA, Rolim JP, Passos VF, Lima RA, Zanin IC, Codes BM, et al. Photodynamic antimicrobial chemotherapy and ultraconservative caries removal linked for management of deep caries lesions. Photodiagnosis Photodyn Ther. 2015 Dec;12(4);581-6. [PubMed]

16. Ricatto LGO, Conrado LAL, Turssi CP, Franca FMG, Basting RT, Amaral FLB. Comparative evaluation of photodynamic therapy using LASER or light emitting diode on cariogenic bacteria: An in vitro study. Eur J Dent. 2014 Oct;8(4):509-514. [PubMed]

Please cite this article as: Lazarova Z, Rashkova M, Gergova G, Stavros Tsitou V-M. Antimicrobial Effect of a Means for Enzyme Excavation (Brix 3000) and Photodynamic Therapy in Carious Lesions of Primary Teeth - in vitro Experiment. J of IMAB. 2021 Oct-Dec;27(4):4048-4051. DOI: https://doi.org/10.5272/jimab.2021274.4048

Received: 19/04/2021; Published online: 18/10/2021

Address for correspondence:

Zornitsa Branimirova Lazarova

Department of Pediatric Dentistry, Faculty of dental medicine, Medical University - Sofia; 1, Georgi Sofiisky str., Sofia, Bulgaria

E-mail: z.lazarova@fdm.mu-sofia.bg, 